\title{
Effect of Access to Obstetrical Care in Rural Alabama on Perinatal, Neonatal, and Infant Outcomes: 2003-2017
}

Jobn B. Waits, MD

Lacy Smith, MD

Daniel Hurst, $P b D$

Cahaba Medical Care

Centreville, Alabama

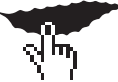

MORE ONLINE

www.annfammed.org
Conflicts of interest: authors report none.

\section{CORRESPONDING AUTHOR}

John B. Waits, MD

Cahaba Medical Care

405 Belcher Street

Centreville, AL 35042

John.Waits@cahabamedicalcare.com

\begin{abstract}
PURPOSE To evaluate differential mortality outcomes in rural Alabama counties with or without access to a local labor and delivery (LED) unit.

METHODS This retrospective cohort study used county-level data from the Alabama Department of Public Health. Rural counties in Alabama were categorized into those with an LED unit and those without. The 2 groups were compared based on infant mortality rate, perinatal mortality rate, neonatal mortality rate, and low birth weight.
\end{abstract}

RESULTS The infant mortality rate from 2003-2017 in the rural counties in Alabama with no local obstetrical care was 9.23 per 1,000 live births, whereas the infant mortality rate during the same period in the rural counties with continuous access to local obstetrical units was 7.89 (relative risk [RR] = 1.1679; $95 \% \mathrm{Cl}, 1.0643-1.2817, P=0.0011)$. The percentage of low birth weight babies from the time period 2003-2014 in the rural counties in Alabama with no local obstetrical care was $10.61 \%$, compared with $9.86 \%$ in the rural counties with continuous access to local LED services ( $R R=1.0756 ; 95 \% \mathrm{Cl}, 1.0424-1.1098$, $P<.0001)$. The perinatal mortality rate in counties with no active LED was 10.82 per 1,000 still + live births compared with 8.89 in counties with an active $\mathrm{LED}(\mathrm{RR}=1.2149 ; 95 \% \mathrm{Cl}, 1.1147-1.3242 ; \mathrm{P}<.0001)$. The neonatal mortality rate during this period was 5.67 per 1,000 live births in counties with no active $L E D$, vs 4.74 in those counties with $L E D$ services $(R R=1.1953 ; 95 \% C l, 1.0609$ 1.3466; $P=0.0034)$.

CONCLUSION Access to local obstetrical care in a rural area is associated with better infant outcomes.

Ann Fam Med 2020;18:446-451. https://doi.org/10.1370/afm.2580.

\section{INTRODUCTION}

$\mathrm{P}$ roviding quality health care access to rural populations is a challenging enterprise. While rural areas cover $97 \%$ of US land area, they contain merely one-fifth of the country's population, equating to about 60 million people. ${ }^{1}$ The US Census Bureau identifies 2 types of urban areas: urbanized areas $(50,000$ or more people) and urban clusters (2,500-50,000 people). ${ }^{1}$ A rural area is simply a territory not included within an urban area. Rural communities face certain challenges, mainly limitations and inequalities, that urban centers do not have. Disparities in health care are often magnified in the rural setting, as access to local health services can be sparse. This disparity is vividly seen in the continued decline in access to local obstetric services in rural US counties, which has been the trend for many years. ${ }^{2}$

It is also noted that the United States' infant mortality rates are among the worst of nations belonging to the Organization for Economic Cooperation and Development (OECD). ${ }^{3}$ This is notable, as the purpose of the OECD is to promote policies that will improve the economic and social well-being of persons globally, and it provides a benchmark to measure where the United States is relative to this stated goal. Of the 35 OECD countries with data reported on infant mortality rates, the United 
States ranks 32nd, with a 2015 infant mortality rate of 5.9 deaths/1,000 live births (which improved to $5.7 \mathrm{i}$ n 2018). ${ }^{4}$ Further, within the United States, Alabama ranks among the states with the highest infant mortality rates, with a 2018 rate of 7.0 deaths/1,000 live births. While this is the lowest infant mortality rate ever recorded in Alabama, the state ranks 45th of the 50 United States. ${ }^{5,6}$ This article reviews the current literature about access to obstetrical care in the rural US setting, focusing specifically on Alabama, and reports on the impact that access to local maternity services has on infant outcomes. As Alabama continues to see a troubling trend in rural labor and delivery (L\&D) closures, this article analyzes the difference in infant outcomes between those rural Alabama counties with a L\&D unit, and those without, in hopes of drawing conclusions about the impact of further closures on future infant outcomes.

\section{Background}

Over one-half of all rural counties in the United States have no obstetric services at their local hospital. There was a $9 \%$ loss of local L\&D services from 2004 through $2014,{ }^{2}$ in addition to previously reported $20 \% \mathrm{~L} \& \mathrm{D}$ closure rate in rural hospitals (1984-1989). ${ }^{7}$ These closures remain multi-factorial, and are associated with both community and hospital financial issues, malpractice premiums for both hospitals and physicians, and nursing, anesthesia, and physician shortages. ${ }^{8}$

Physician shortages in rural areas are a significant barrier to accessing obstetrical care. In 2008, the latest year such data was available, only $6.4 \%$ of obstetrician-gynecologists practiced in rural settings. ${ }^{9}$ In $2010,49 \%$ of the 3,143 US counties lacked an obstetrician-gynecologist. These counties are predominantly rural, often situated in areas of the rural south, Midwest, and mountain states..$^{10}$ In these contexts, it is common for family physicians, whose training includes vaginal, and often cesarean, deliveries to provide maternity care. In some rural areas, including the author's community of Centreville, in central Alabama, family physicians provide $100 \%$ of obstetric care. Some family physicians have completed additional surgical and high-risk pregnancy training in a post-residency obstetrics fellowship. Nonetheless, though family physicians are essential for fulfilling the void of obstetric care in rural areas, data show that obstetric services provided by family physicians are steadily decreasing. The American Board of Family Medicine reported in 2000 that approximately 23\% of family physicians provided some maternity care, but by 2010 this rate had declined to less than $10 \%$. This precipitous decline is alarming as family physicians are the most widely distributed medical specialists and are essential to health care access in the rural context. ${ }^{11-18}$

In rural areas, disparity in access to care is not only associated with physician shortage, but is concurrent with closure of hospital obstetrics or L\&D units. The phenomenon of declining rural obstetric care has been reported at length. ${ }^{19,20} \mathrm{~A}$ recent study of over 300 rural hospitals found that $7.2 \%$ closed their obstetric units from 2010 through $2014 .^{8}$ This decline is alarming and was associated with increases in out-of-hospital and preterm births and births in hospitals without obstetric units in the following year. ${ }^{21}$

Within the state of Alabama, there has been a precipitous and sustained decline in local obstetrics units in rural hospitals since the mid-1980s. In 1980, 58 of the 67 Alabama counties had at least one L\&D unit providing obstetric services. By 2016, however, this number decreased to merely 30 counties (Supplemental Figure 1, https://www.AnnFamMed.org/ content/18/5/446/suppl/DC1/).

This article aims to evaluate obstetrical care in the primarily rural state of Alabama over a 15 -year period with the hypothesis that lack of access to local obstetrical services is associated with worse infant outcomes. We chose to examine infant mortality, low birth weight, perinatal mortality, and neonatal mortality, for this analysis. These 4 outcomes were chosen as published data was either readily available on the web or obtained from the state Public Health Office. ${ }^{23}$ The low birth weight data was not publicly presented after the 2014 report, and thus only 2003-2014 is analyzed in this paper. Maternal mortality was not published in the state over this time period, nor was availability of prenatal care. Also, the adequacy of prenatal care had a definition that altered significantly during the time period under investigation.

While the definition of rural promulgated by the Office of Primary Care and Rural Health, the Alabama Department of Public Health (ADPH), and the Alabama Rural Health Association is more locally accurate in our estimation, for this study, we chose to eliminate the cohort of rural counties that the Office of Management and Budget considers to be in a Metropolitan Statistical Area in an effort to avoid overlap and differing definitions of what constitutes rural. It is important to note that this categorization, due to the way that the Office of Management and Budget defines a Metropolitan Statistical Area, potentially vastly underrepresents the number of the people who would self-identify as living in a rural area population. The definitions used for the term rural have far-reaching policy implications and can result in outcomes that are different from those intended. ${ }^{25}$ 


\section{METHODS}

\section{Population Studied}

A cohort of rural Alabama counties with no in-county obstetrical services available (data reported in ADPH reports) during the period from 2003 through 2017 was compared with a control cohort of counties with continuously available obstetrical services over the same period. This 15 -year period was chosen based on accessibility of the data (no ADPH data on the website before 2003 or after 2017).

The Office of Primary Care and Rural Health, $\mathrm{ADPH}$, and the Alabama Rural Health Association categorized 55 of 67 Alabama counties as rural. ${ }^{26}$ Many of these counties, however, are included as a part of a Metropolitan Statistical Area according to the Federal Office of Rural Health Policy ${ }^{27}$ and the US Census Bureau. Initially, 28 of 67 counties were excluded for being either urban or part of a Metropolitan Statistical Area and thus considered urbanized by the Office of Management and Budget.

The remaining 39 Alabama counties were the following: Baldwin, Barbour, Bullock, Butler, Chambers, Cherokee, Choctaw, Clarke, Clay, Cleburne, Coffee, Conecuh, Coosa, Covington, Crenshaw, Cullman, Dale, Dallas, DeKal, Escambia, Fayette, Franklin, Jackson, Lamar, Macon, Marengo, Marion, Marshall, Monroe, Perry, Pickens, Pike, Randolph, Sumter, Talladega, Tallapoosa, Washington, Wilcox, and Winston.

Of these, 3 counties (Cherokee, Crenshaw, and Marengo) that had L\&Ds close either during the

Table 1. Locally Available vs Unavailable LED Services for Rural Alabama Counties, 2003-2017 ( $N=36)$

\begin{tabular}{ll}
\hline Counties With LED $(\mathbf{n}=\mathbf{1 5})$ & Counties With No LED $(\mathbf{n = 2 1 )}$ \\
\hline Baldwin, Chambers, Clarke, Cof- & Barbour, Bullock, Butler, Chocta, Clay, \\
fee, Covington, Cullman, Dal- & Cleburne, Conecuh, Coosa, Dale, Fay- \\
las, DeKalb, Escambia, Frank- & ette, Lamar, Macon, Marion, Perry, \\
lin, Jackson, Marshall, Monroe, & Pickens, Pike, Randolph, Sumter, Wash- \\
Talladega, Tallapoosa & ington, Wilcox, Winston \\
\hline LED = labor and delivery. & \\
\hline
\end{tabular}

Table 2. Comparison of Demographics of Rural Alabama Counties by LED Service Availability, 2003-201728 $(\mathrm{N}=36)$

\begin{tabular}{lcc}
\hline Characteristic & $\begin{array}{c}\text { Counties With } \\
\text { LED (n= 15) }\end{array}$ & $\begin{array}{c}\text { Counties With No } \\
\text { LED (n = 21) }\end{array}$ \\
\hline Mean population (2010), No. & 19,751 & 59,240 \\
White, \% & 60.86 & 73.47 \\
Black or African American, \% & 36.23 & 22.76 \\
Latino and Hispanic, \% & 2.78 & 5.48 \\
Median income (2014-2018), \$ & 35,604 & 40,759 \\
Per Capita income (2014-2018), \$ & 20,641 & 22,474 \\
\hline LED = labor and delivery. & & \\
\hline
\end{tabular}

measurement period or immediately prior were excluded from analysis, leaving 36 counties in the study. The availability of L\&D services in each of the 36 counties was determined from publicly available information of the ADPH. Counties having a minimum of $1 \mathrm{~L} \& \mathrm{D}$ unit were considered to have locally available L\&D services (Table 1). Available demographic data was compared between available vs unavailable L\&D by county in Alabama, 2003-2017 (Table 2).

Home births are not a statistically significant feature of obstetrics in Alabama, partly due to the fact that there were no midwives licensed to attend home births in Alabama from 1976 until 2017. ${ }^{29}$ Countylevel data was obtained from ADPH electronic publications available to the public. ${ }^{23}$ The source of the data in the ADPH publications are primarily from death certificates. Two authors (J.B.W., D.H.) ensured that data was retrieved and transferred accurately from ADPH.

\section{Outcomes}

Outcomes were defined as follows. ${ }^{24}$ Infant Mortality Rate refers to the number of deaths of infants under age 1 year per 1,000 live births in a given year. Stillbirths were the death of a fetus weighing at least $500 \mathrm{~g}$ when birth weight was available, or death after 22 complete weeks of gestation, or fetuses having crown-heel length of $25 \mathrm{~cm}$ or more before the complete expulsion or extraction from the mother. Perinatal Mortality Rate refers to the number of stillbirths or deaths of infants under age 1 week per 1,000 still and live births in a given year. This rate avoids the difficulty of defining a live birth and combines late fetal and early neonatal deaths. Neonatal Mortality Rate refers to the number of deaths in the first 28 days of life per 1,000 live births in a given year.

\section{Statistical Analysis}

Differences in relative risk of outcome between rural counties with locally available L\&D services vs those without were evaluated using statistical analysis in MedCalc (MedCalc Software Ltd).

\section{RESULTS}

The outcomes comparing rural Alabama counties with and without L\&D services are summarized in Table 3.

The infant mortality rate from 2003 2017 in the rural counties of Alabama with no obstetrical care was 9.23 per 1,000 live 


\begin{tabular}{|c|c|c|}
\hline Outcome Measure & $\begin{array}{l}\text { Counties } \\
\text { With LED }\end{array}$ & $\begin{array}{c}\text { Counties } \\
\text { With No LED }\end{array}$ \\
\hline Infant MR, No. per 1,000 & 7.89 & 9.23 \\
\hline Live births, No. & 165,525 & 72,177 \\
\hline Infant deaths, No. & 1,306 & 666 \\
\hline Low birth weights, $\%$ & 9.86 & 10.61 \\
\hline Live births, No. & 111,393 & 48,568 \\
\hline Low birth weights, No. & 10,986 & 5,152 \\
\hline Perinatal MR, No. per 1,000 & 8.89 & 10.82 \\
\hline Live + still births, No. & 165,525 & 1,479 \\
\hline Perinatal deaths, No. & 72,659 & 786 \\
\hline Neonatal MR, No. per 1,000 & 4.74 & 5.67 \\
\hline Live births, No. & 166,425 & 72,177 \\
\hline Neonatal deaths, No. & 784 & 409 \\
\hline
\end{tabular}

$\mathrm{LED}=$ labor and delivery; $\mathrm{MR}=$ mortality rate.

a Data for low birth weights only available for 2003-2014.

births, compared with a rate of 7.89 per 1,000 live births in rural counties with continuous access to L\&D services $(\mathrm{RR}=1.1679 ; 95 \% \mathrm{CI}, 1.0643-1.2817$, $P=0.0011$.

The percentage of low birth weight babies born from 2003-2014 (years that data was available) in the rural counties of Alabama with no L\&D services was $10.61 \%$, compared with $9.86 \%$ in the rural counties with continuous access to $\mathrm{L} \& \mathrm{D}$ services $\left(\mathrm{RR}=1.0756_{\text {; }}\right.$ 95\% CI, 1.0424-1.1098, $P<0.001$ ).

The perinatal mortality rate from 2003-2017 in rural Alabama counties with no L\&D services was 10.82 per 1,000 still + live births compared with 8.89 per 1,000 still + live births in rural counties with continuous access to $\mathrm{L} \& \mathrm{D}$ services $(\mathrm{RR}=1.2149 ; 95 \% \mathrm{CI}$, $1.1147-1.3242 ; P<.0001)$.

The neonatal mortality rate assessed from 20032017 in rural counties with no L\&D services was 5.67 neonatal deaths per 1,000 live births compared with a rate of 4.74 in counties with continuous access to L\&D services $(\mathrm{RR}=1.1953 ; 95 \% \mathrm{CI}, 1.0609-1.3466$; $P=0.0034)$.

Additional demographic, clinical, and social data was not available.

\section{DISCUSSION}

Rural Alabama counties with no labor and delivery unit over the 15-year time span of 2003-2017 had statistically significant higher rates of infant mortality, as well as more low birth weights, and neonatal and perinatal mortality. While even strong correlations cannot prove causation, this correlation is consistent with a mature ${ }^{30}$ and growing body of data ${ }^{31}$ that points in the same direction, and deserves broad public discussion.

The rural population struggles with, not only a shortage of physicians, but also a declining number of practitioners and hospitals who offer obstetric services. ${ }^{8}$ The primary care physician-to-patient ratio in nonmetropolitan areas stands at 39.8 physicians per 100,000 people, compared with 53.3 physicians per 100,000 in metropolitan centers. ${ }^{32}$ This maldistribution of physicians may have negative impacts on the health of the rural population. One negative impact is not having $L \& D$ services available within the county. This lack is correlated with an increased infant mortality rate and lower birth weights. While causation between lack of availability of $\mathrm{L} \& \mathrm{D}$ services and adverse perinatal outcomes cannot be directly determined by this study, the discrepancy in outcome with statistical significance is noteworthy.

This study has certain limitations. First, as noted above, the design of this type of correlation study does not permit a definitive conclusion that a causal relationship exists. Nesbitt and colleagues have provided a thorough explanation of this, noting that there are alternate explanations for a correlation between access to L\&D services and adverse outcomes. ${ }^{29} \mathrm{Sec}$ ond, we are aware that other variables may factor into this issue, such as driving distance to the nearest hospital with an L\&D unit, or locally available and adequate prenatal care. Driving distances to the nearest L\&D unit, as well as travel of patients to the nearest hospital and/or hospitals (each rural county having more than 1 pattern) would be needed to further understand this issue, but the data was unavailable. Third, data on whether or not prenatal care was locally available was unavailable and could not be accounted for in the study. Fourth, the definitions of adequacy of prenatal care changed over the study period, as did the public reporting of this measure at the county level. For these reasons, while we were interested in these issues, we elected to use the more definitive mortality rates, believing that any difference detected in those would be stronger, and the other issues could be the subject of future study. Furthermore, the rural counties with no L\&D over the timespan have a median income (overall and per capita) similar to the counties with an L\&D. The counties without an $\mathrm{L} \& \mathrm{D}$, however, have a higher percentage of underrepresented minorities, which could contribute to a worse mortality rate as well. Finally, the definition of rural is a controversial issue, with differing definitions existing across governmental agencies. To avoid any confusion, we chose the more restrictive Federal definition of rurality provided by the Office of Management and Budget. Enhanced consensus on 
the definition of rural across governmental agencies would be beneficial when studying effects or impacts of events on rural communities.

\section{CONCLUSIONS}

This study presents a strong and statistically significant correlation between absence of locally available labor and delivery services and adverse perinatal outcomes as measured by infant mortality rate, low birth weight rate, perinatal mortality rate, and neonatal mortality rate. If a causal relationship does exist, then rural populations would definitively benefit from having local access to a L\&D unit within their community. This may offer a rationale for more urgent policy planning and recommendations, as well as caution for the current trend of diminishing $L \& D$ units that is occurring in many rural settings, in order to improve the health outcomes of women and children in the United States.

\section{To read or post commentaries in response to this article, see it} online at https://www.AnnFamMed.org/content/18/5/446.

Key words: health care quality, access, and evaluation; infant mortality; obstetrics; perinatal mortality; rural health

Submitted December 9, 2019; submitted, revised, February 27, 2020; accepted March 10, 2020.

Acknowledgments: We would like to thank Dallis Jones-Vanderslice for substantially assisting in compiling much of the data for this project, as well as Jason Stevens for his hard work in recreating and updating the map from the Alabama Department of Public Health. We want to acknowledge the Alabama Family Practice Rural Health Board for providing a starter grant to one of the authors (J.B.W.) a decade ago that assisted in getting this line of research started. Also, we would not have been able to do this study without the help of the statisticians from the Alabama Department of Public Health. Lastly, we are grateful for the comments of the anonymous reviewers who offered feedback and suggestions on how to improve the paper.

Supplemental materials: Available at https://www.AnnFamMed. org/content/18/5/446/suppl/DC1/.

\section{References}

1. United States Census Bureau. New census data show differences between urban and rural populations. https://www.census.gov/news room/press-releases/2016/cb16-210.html. Published Dec 8, 2016. Accessed Nov 1, 2019.

2. Hung $P$, Henning-Smith CE, Casey MM, Kozhimannil KB. Access to obstetric services in rural counties still declining, with 9 percent losing services, 2004-14. Health Aff (Millwood). 2017;36(9):1663-1671.

3. America's Health Rankings. 2016 annual report. https://www.americas healthrankings.org/learn/reports/2016-annual-report/comparisonwith-other-nations. Published 2016. Accessed Nov 1, 2019.

4. Organisation for Economic Co-Operation and Development (OECD). Infant mortality rates. https://data.oecd.org/healthstat/infantmortality-rates.htm. Accessed Nov 1, 2019.

5. Alabama Department of Public Health. Infant mortality. https:// www.alabamapublichealth.gov/perinatal/infant-mortality.html. Updated Jan 15, 2020. Accessed Feb 26, 2020.
6. Centers for Disease Control and Prevention (CDC). Infant mortality rates by state. https://www.cdc.gov/nchs/pressroom/sosmap/infant_ mortality_rates/infant_mortality.htm. Published 2016. Accessed Nov 1, 2019.

7. Institute of Medicine Committee to Study Medical Professional Liability and the Delivery of Obstetrical Care. The Effect of Medical Professional Liability on the Delivery of Obstetrical Care. Washington, DC: National Academies Press; 1989. https://www.ncbi.nlm.nih.gov/ books/NBK218671/. Accessed Nov 1, 2019.

8. Hung P, Kozhimannil KB, Casey MM, Moscovice IS. Why are obstetric units in rural hospitals closing their doors? Health Serv Res. 2016; 51(4):1546-1560.

9. American College of Obstetricians and Gynecologists. Health Disparities in Rural Women. Committee Opinion Number 586. February 2014. (Reaffirmed 2016. Replaces Committee Opinion Number 429, March 2009). https://www.acog.org/clinical/clinical-guidance/ committee-opinion/articles/2014/02/health-disparities-in-ruralwomen. Accessed Nov 1, 2019.

10. American College of Obstetricians and Gynecologists. Committee opinion: health disparities in rural women. https://www.acog.org/ Clinical-Guidance-and-Publications/Committee-Opinions/Committeeon-Health-Care-for-Underserved-Women/Health-Disparities-in-RuralWomen\#25. Published Feb 2014. Accessed Nov 1, 2019.

11. Tong ST, Makaroff LA, Xierali IM, et al. Proportion of family physicians providing maternity care continues to decline. J Am Board Fam Med. 2012;25(3):270-271.

12. Larimore W, Griffin E. Family practice maternity care in central Florida: Increased income, satisfaction, and practice diversity. Florida Family Physician. 1993;53(1):28-30.

13. Larimore WL, Sapolsky BS. Maternity care in family medicine: economics and malpractice. J Fam Pract. 1995;40(2):153-160.

14. Rodney WM, Crown LA, Hahn R, Martin J. Enhancing the family medicine curriculum in deliveries and emergency medicine as a way of developing a rural teaching site. Fam Med. 1998;30(10):712-719.

15. Homan FF, Olson AL, Johnson DJ. A comparison of cesarean delivery outcomes for rural family physicians and obstetricians. J Am Board Fam Med. 2013;26(4):366-372.

16. Avery DM. The history of board certification of family medicine obstetricians. Am J Clin Med. 2009;6(2):8-10.

17. Loafman M, Nanda S. Who will deliver our babies?: crisis in the physician workforce. Am J Clin Med. 2009;6(2):11-16.

18. Rodney WM, Martinez C, Collins M, Laurence G, Pean C, Stallings J. OB fellowship outcomes 1992-2010: where do they go, who stops delivering, and why? Fam Med. 2010;42(10):712-716.

19. Rivers PA. Access to obstetrics care for rural Alabama population. Int J Health Plann Manage. 1998;13(4):277-288.

20. Hung P, Kozhimannil K, Henning-Smith C, Casey M. Closure of hospital obstetric services disproportionately affects less-populated rural counties. University of Minnesota Rural Health Research Center. https://rhrc.umn.edu/wp-content/files_mf/1491501904UMRHRCOB closuresPolicyBrief.pdf. Published Apr 2017. Accessed Nov 1, 2019.

21. Kozhimannil KB, Hung P, Henning-Smith C, Casey MM, Prasad S. Association between loss of hospital-based obstetric services and birth outcomes in rural counties in the United States. JAMA. 2018; 319(12):1239-1247.

22. Alabama Department of Public Health. A picture of the loss of rural obstetrical service in Alabama since 1980. https://arhaonline.files. wordpress.com/2018/07/obstetrics-comparison-1980-today-1.pdf. Published 2011. Accessed Nov 1, 2019.

23. Alabama Department of Public Health. Health Statistics - Publications. https://www.alabamapublichealth.gov/healthstats/ publications.html. Updated Feb 28, 2020. Accessed Feb 26, 2020.

24. Overview of obstetrics. In: Cunningham F, Leveno K, Bloom S, et al, eds. Williams Obstetrics. 25 ed. New York, NY: McGraw-Hill; 2018:2-13. 
25. Coburn A, MacKinney A, McBride T, Mueller K, Slifkin R, Wakefield $M$. Issue Brief \#2: Choosing rural definitions: implications for health policy. Rural Policy Research Institute Health Panel. https://www. rupri.org/Forms/RuralDefinitionsBrief.pdf. Published Mar 2007. Accessed Nov 1, 2019.

26. Alabama Department of Public Health, Alabama Rural Health Association. Selected indicators of health status in Alabama; Alabama's rural and urban counties. https://www.adph.org/ruralhealth/assets/ StatewideReport.pdf. Published Oct 2007. Accessed Nov 1, 2019.

27. Health Resources $\&$ Services Administration (HRSA). Defining rural population. https://www.hrsa.gov/rural-health/about-us/definition/ index.html. Updated July 2020. Accessed Nov 1, 2019.

28. United States Census Bureau. Quick Facts; Baldwin County, Alabama. https://www.census.gov/quickfacts/fact/table/baldwincounty alabama/PST045219. Accessed Feb 26, 2020.
29. Vollers AC. Midwives can legally deliver Alabama babies for first time in decades as state issues licenses. https://www.al.com/ news/2019/01/midwives-can-legally-deliver-alabama-babies-for-firsttime-in-decades-as-state-issues-licenses.html. Published Jan 2019. Accessed Feb 26, 2020.

30. Nesbitt TS, Connell FA, Hart LG, Rosenblatt RA. Access to obstetric care in rural areas: effect on birth outcomes. Am J Public Health. 1990;80(7):814-818.

31. Powell J, Skinner C, Lavender D, Avery D, Leeper J. Obstetric care by family physicians and infant mortality in rural Alabama. J Am Board Fam Med. 2018;31(4):542-549.

32. Hing $E$, Hsiao C. NCHS data brief: state variability in supply of officebased primary care providers: United States 2012. US Department of Health and Human Services. https://www.ruralhealthweb.org/ NRHA/media/Emerge_NRHA/PDFs/db151.pdf. Published May 2014. Accessed Nov 1, 2019.

\section{Get the Annals of} Family Medicine by E-mail

Editorials । Original Research | Research Briefs I Systematic Reviews I Reflections I Innovations I Departments

\section{Editorial Fellowship: Now accepting applications}

The full text of the joumal is available online at hitto://www.annfammed.org and through various aggregators, including PubMed Central, EBSCO, and MDConsult. The Annals is indexed in the MEDLINE, Science Citation Index Expanded, Current Contents/Clinical Medicine, EMBASE, and CINHAL databases.

\section{EDITORIALS}

In This Issue: Nothing Simple Kurt C. Stange

The Long Loneliness of Primary Carey Timothy P. Daaleman

Clinical Prediction Rules: Challenges, Barriers, and Promises Emma Wallace; Michael E. Johansen

\section{ORIGINAL RESEARCH}

Social Isolation and Patient Experience in Older Adults

Takuya Aoki; Yosuke Yamamoto; Tatsuyoshi Ikenoue; Yuka Urushibara-Miyachi; Morito Kise; Yasuki Fujinnuma; Shunichi Fukuhara

Social isolation is associated with a negative patient experience in older primary care patients in Japan. 